\title{
A review on advances in design and development of complex adaptive systems for healthcare using concept maps
}

\author{
Varadraj P. Gurupur \\ School of Global Health Management and Informatics, University of Central Florida, Orlando, FL, USA \\ Correspondence to: Varadraj P. Gurupur. School of Global Health Management and Informatics, University of Central Florida, Orlando, FL, USA. \\ Email: varadraj.gurupur@ucf.edu.
}

\begin{abstract}
The purpose of this paper is to demonstrate the unique contributions made by several researchers including the author to the design and development of complex adaptive systems for healthcare. The article first presents definitions of complex adaptive systems and associated terms provided by other scholars. This is followed by a discussion on the ideas that lead to the development of different complex adaptive systems. This discussion includes unique contributions to systems engineering applied to healthcare information systems. A further elaboration on these unique contributions made by these systems considering applications such as Concept Map-Based Personal Health Information System (C-PHIS) and Data Completeness Analysis Package (DCAP) is presented. Here the author provides emphasis on advances in the design and development of complex adaptive systems using concept maps. This discussion also includes their applications in critical segments of healthcare delivery such as dementia and mental health. Finally, a pathway for future research work in this field of research is discussed to provide new insights on a possible roadmap for advancing the science of complex adaptive systems. Overall, the article presents a few critical ideas and contributions thereby adding to the body of knowledge associated with complex adaptive systems applied to healthcare information systems. Also, anticipate the unexpected and deal with outcomes of system engineering in complex adaptive systems with respect to healthcare.
\end{abstract}

Keywords: Complex adaptive systems; healthcare decision making; concept maps

Received: 30 November 2020; Accepted: 20 April 2021; Published: 10 May 2021.

doi: $10.21037 / \mathrm{ht}-21-12$

View this article at: http://dx.doi.org/10.21037/ht-21-12

\section{Introduction}

Dooley (1) defines Complex Adaptive Systems as "a group of semi-autonomous agents who interact in interdependent ways to produce system-wide patterns, such that those patterns then influence behavior of the agents". In this definition if we must conceive agents as systems or more precisely as sub-systems of a larger system. In other words, a complex adaptive system is just another example for a system of systems. Boulding (2) informed the community of scientists and philosophers about the hierarchy of complexity which was further quoted by more recently by Keating et al. (3) to illustrate the definition of system of systems as, "the arrangement of theoretical systems and constructs in a hierarchy of complexity." Keating et al. (3) emphasize that Boulding presented the idea of system of systems as having static structural components while having dynamic dimensions. Thereby, allowing a systems engineer to accept the fact that a complex adaptive system also consists of complexity, hierarchy, and dynamic dimensions. A key differentiating factor between an ordinary system of systems and a complex adaptive system is that the complex adaptive system adapts itself to its environment or in other words enables automatic or semi-automatic self-modification based on the changes in its operating environment. From this perspective Chan (4) states that "there is no separation between a system and its environment in the idea that a system always adapts to a changing environment." On this context, Ellis and Herbert (5) 
identify the key features of Complex Adaptive Systems as: (I) existence of informal collaborative networks, holistic patterns, causality, feedback, emergent behavior, and hierarchy.

In a more recent work Complex Adaptive System model has been defined by Carmichael et al. (6) as "having a significant number of self-similar agents that: (I) utilize one or more levels of feedback, (II) exhibit emergent properties and self-organization, and (III) produce non-linear dynamic behavior." From this definition we observe the metamorphosis in the definitions associated with complex adaptive systems. Although, the definition here pertains to a model where complex adaptive systems are applied a reader can observe the inclusion of concepts such as feedback, self-organization, and dynamic behavior. This provides a further emphasis on adaptation of the system based on the environment in which the system exists. If we must assume that a particular complex adaptive system pertains to a specific domain of knowledge then changes, improvements, and additions to it must reflect on the functioning of the system. On this matter Gurupur et al. (7) have demonstrated the usefulness of concept maps to achieve this purpose.

\section{Use of concept maps in design and development of complex adaptive systems}

Ruiz-Primo et al. (8) define a concept map as a "graphical representation consisting of nodes and labeled lines". Concept maps are used in knowledge systems based on the idea presented by Anderson (9) that states "the essence of knowledge is structure". On this note, Gurupur et al. (7) have demonstrated how concept maps can been used to develop complex adaptive systems. It is important to mention that concept maps can play a vital role in knowledge representation from a domain expert. An important aspect of using concept maps is that it allows the domain expert to easily modify the concept map thereby reflecting an updated version of the domain knowledge. Gurupur et al. (7) have demonstrated the use of this idea on developing Personal Health Information Systems. From this perspective, Albert and Steiner (10) were among the first to demonstrate the use of concept maps to represent domain knowledge. Here the investigators attempt to answer a key question that pertains to the reliability of the concept map with respect to the domain knowledge represented. The reliability of the domain knowledge is ascertained by having two or more domain experts develop a concept map for the same domain of knowledge. A match between these maps would ascertain the reliability of the concept maps developed. Validity of a concept map is divided into two parts: content validity and application validity. Content validity is examined by judging the required criteria and if the content pertains to that criteria. In other words, the investigator is attempting to examine if the creator of the concept map is somehow digressing from the topic of conversation. Application validity dwells on the idea of situational performance where the investigator tries to ascertain if the individual concept map developer has a high-performance score in that knowledge domain. This performance score can be derived from quizzes, standard tests, and other such individual test criterion.

The importance of the discussion on the validity and the reliability of the concept map dwells in the fact that the reliability of the complex adaptive system will depend on the reliability of the knowledge represented in the form of a concept map. Here it is important to note that domain knowledge can be complex and representation of domain knowledge using concept maps means dealing with that inherent complexity emanating from the knowledge domain. While discussing complexity it is important to mention that Herbert Simon (11) in his seminal work titled, "The Architecture of Complexity" informs the community of scientists that complexity takes the form of hierarchy. In 2013, Yao and Gu (12) delineated on how ontologies developed using tools such as Protégé can be transformed into concept maps. This work provided included explanations using mathematical formulations with key steps involved mathematically representing concept maps. Khayut et al. (13) advance this thinking by illustrating the idea that a Complex Adaptive System must represent information or knowledge that must allow fuzzy thinking. Aajli (14) illustrated the use of fuzzy logic to represent the relevance degree of relationships within a concept map. This clearly indicates that complex knowledge and problems can be represented using concept maps in developing complex adaptive systems. To further expand this discussion, Žubrinić (15) has provided an illustration on the automation of concept map development from both textual and nontextual sources. In this work the investigator delineates an eight-step approach in performing this task. This work is of much importance since it identifies a theoretical pathway for concept map automation. However, it is important to note that this may not be a panacea for concept map automation given the complexity of the knowledge derived from the universe of discourse for an individual complex adaptive system. 


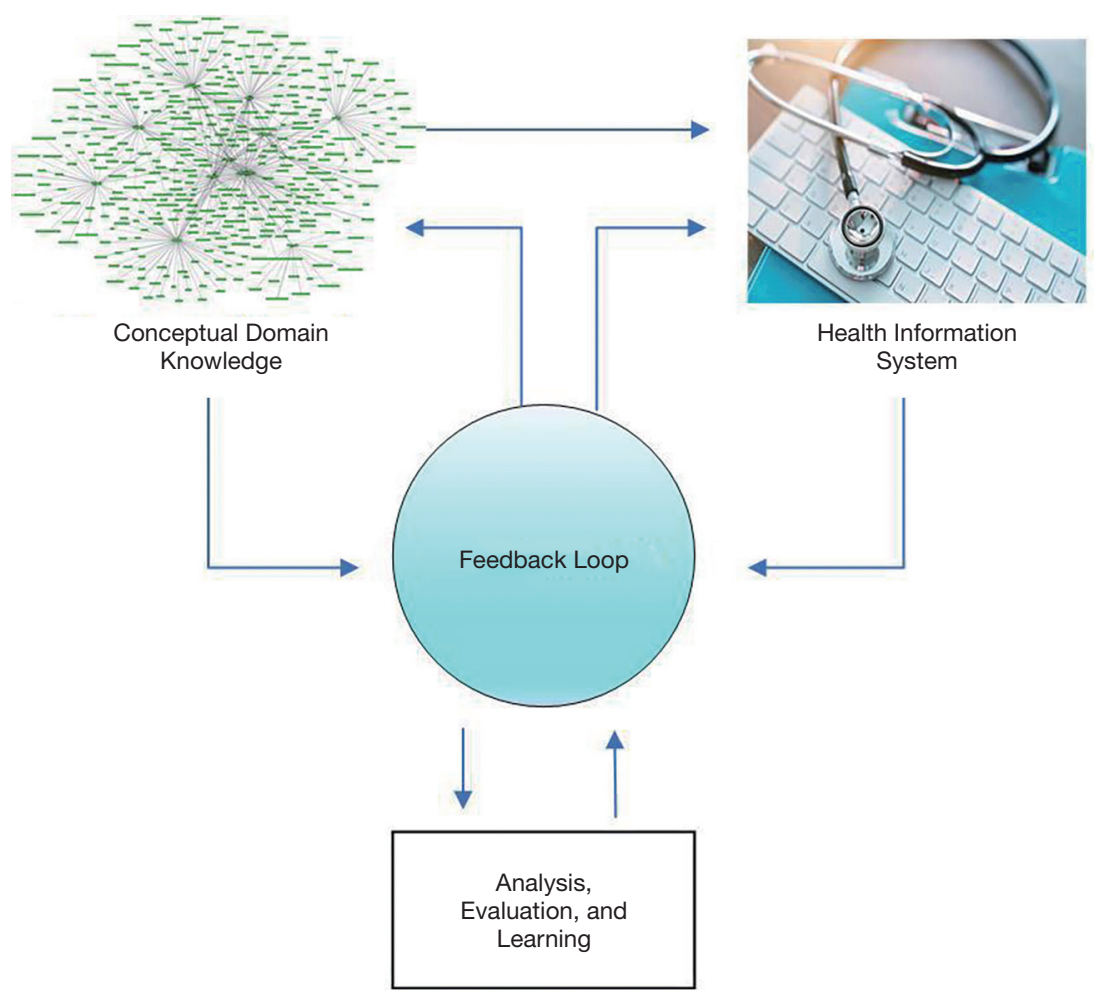

Figure 1 General architecture of complex adaptive systems for healthcare using concept maps.

\section{Complex adaptive systems for healthcare using concept maps}

Figure 1 illustrates the general structure of a complex adaptive system for healthcare based on the research work carried out by the author $(7,16-18)$. Here in this general architecture the domain knowledge is first captured with the help of a domain expert. This knowledge controls the behavior of the health information system (19). A feedback loop that involves analysis and evaluations (20) indicating if the system is making the right recommendations is built into the system. This general architecture has been used by the author many of his research works.

From an application perspective, Gurupur et al. (7) illustrated the use of concept maps in designing Personal Health Information Systems (PHIS). Given the fact that the PHIS involve capturing of complex domain knowledge that needs periodic updating and involves a feedback loop with different parts of the PHIS functioning as autonomous agents, PHIS can be perceived as a Complex Adaptive System. Interestingly, in a more recent work LaNoue (16) illustrates the use of concept map in improving clinical quality improvement engaging patients. In this work the authors provide emphasis on brain storming, structuring of the information received, interpretation, and use. In contrast to the method discussed by Žubrinić (15) where information is available in an electronic form, here the authors discuss gathering information from human conversations for the purpose of concept map development with an intention of improving processes within the healthcare ecosystem.

An important aspect of developing knowledge systems using concept maps will be ascertaining the strength and validity of the concept map. As discussed before, Albert and Steiner (10) have already provided a path for measuring the validity and reliability of the concept map. An illustration on measuring the strength of the concept map was provided by Gurupur et al. $(17,18)$. This research provides insights on measuring the strength of the connectivity of concepts for a healthcare application. The investigators involved in this work attempt to ascertain the depth of knowledge without focusing on validity, and reliability. The reason for not attempting to measure validity and reliability is based on the idea that the knowledge provided by the domain expert will not require further validation.

The concept of relying on the domain expert has been illustrated by Karla and Gurupur (19). Karla coined his 
system as C-PHIS where "C" denoted concept maps. In this work the investigators described how concept maps could be used for knowledge generation and implementation of a PHIS. If we perceive a PHIS as a complex adaptive system from a system of systems perspective concept maps work as communicators between individual autonomous systems of the whole. Although the authors here focus on system design and development, they do not describe this phenomenon using appropriate mathematical formulations thereby limiting the necessary contribution to science. It is also important to mention here that this system can be applied where concept maps can capture the necessary behavior of patients and caregivers. This captured behavior can be used to modify the outcome or recommendations made by the system. This is an area of engineering that is worth exploring where a captured patient or caregiver behavior aligns the system in a particular direction of recommendation.

Data completeness analysis package (DCAP) (20) illustrates the use of concept maps in developing a system that analyzes the incompleteness of electronic health record data. In this system concept maps are used to develop a master concept map that identifies a complete electronic health record. With regards to using concept maps in illustrating the factors that lead to mental health illness was carried out by Alafaireet et al. (21). In this work Alafaireet et al. (21) focus on the various domains that affect mental health and the level of intervention required with respect to each domain. The concept map created represents links between these domains along with their impact on mental health. The concept map used in this research work was developed after investigating more than 600 articles. Therefore, this research is another example on how concept maps simplify the representation of complex domain knowledge. This simplification conceptually facilitates its use in driving the knowledge systems of a complex adaptive system.

In a more recent research work Leyns et al. (22) describe the use of concept mapping in clustering policy needs for public health. This work provides a description on capturing necessary information as statements and using these statements in deriving individual concepts and mapping them together to form a concept map. While Alafaireet et al. (21) attempt to perform something similar for mental health associated with recidivism the investigators in this article focus on gathering information by brainstorming instead of extracting it from research articles. This is another evidence of concept maps reducing the complexity of information.
It is also important to note that in the pursuit of reducing complexity there is room for incorporating the details through connected sub concept maps.

Overall, available literature clearly indicates that concept maps can be used in representing complex domain knowledge using various methods. Additionally, we know from the work conducted by Gurupur et al. (7) and Karla et al. (19) that this complex domain knowledge can be integrated into a complex adaptive system.

\section{Conclusions and possible future work}

We have now discussed some relevant work on design and development of complex adaptive systems using concept maps. Noticeably, complex adaptive systems have not been discussed in scientific literature compared to other more general popular perceptions of systems such as knowledgebased systems, rule-based systems, and decision support systems $(23,24)$ which are closely related to the idea of complex adaptive systems. Here the author presents a perception that in different ways a complex adaptive system is a decision support system since it is used in supporting decisions from existing knowledge and new data. Additionally, it is also a knowledge-based system since storing, retrieving, and processing knowledge is key to the functioning of a complex adaptive system, and it can also be conceived as a rule-based system to accommodate tacit, and implicit forms of knowledge (18,25-29).

Based on the discussions presented a key observation made here is presenting systems and experimental work performed by the author and other researchers working on complex adaptive systems in delineating the relevance of using concept maps in different ways for developing these systems. Additionally, it is important to emphasize that use of concept maps to implement a feedback mechanism or a self-learning structure for a complex adaptive system will be a much-needed future effort.

\section{Acknowledgments}

Funding: None.

\section{Footnote}

Conflicts of Interest: The author has completed the ICMJE uniform disclosure form (available at http://dx.doi. org/10.21037/ht-21-12). The author has no conflicts of interest to declare. 
Ethical Statement: The author is accountable for all aspects of the work in ensuring that questions related to the accuracy or integrity of any part of the work are appropriately investigated and resolved.

Open Access Statement: This is an Open Access article distributed in accordance with the Creative Commons Attribution-NonCommercial-NoDerivs 4.0 International License (CC BY-NC-ND 4.0), which permits the noncommercial replication and distribution of the article with the strict proviso that no changes or edits are made and the original work is properly cited (including links to both the formal publication through the relevant DOI and the license). See: https://creativecommons.org/licenses/by-nc-nd/4.0/.

\section{References}

1. Dooley K. A Nominal Definition of Complex Adaptive Systems. Chaos Network 1996;8:2-3.

2. Boulding KE. General Systems Theory-The Skeleton of Science. Management Science 1956;2:197-208.

3. Keating C, Rogers R, Unal R, et al. System of Systems Engineering. Engineering Management J 2003;15:36-45.

4. Chan S. Available online: https://docplayer.net/426415Complex-adaptive-systems.html Last Accessed: 11-292020.

5. Ellis B, Herbert SI. Complex adaptive systems (CAS): an overview of key elements, characteristics and application to management theory. Informatics in Primary Care 2011;19:33-7.

6. Carmichael T, Collins A, Hadzikadic M. editors. Complex Adaptive Systems views from the Physical, Natural, and Social Sciences, Switzerland: Springer Nature, 2019.

7. Gurupur VP, Suh SC, Selvaggi RR, et al. An Approach for Building a Personal Health Information System Using Conceptual Domain Knowledge. J Med Syst 2012;36:3685-93.

8. Ruiz-Primo MA, Shavelson RJ, Schultz SE. On the validity of concept map-base assessment interpretations: An experiment testing the assumption of hierarchical concept maps in science (CSE Report 455). Los Angeles: University of California, Los Angeles, National Center for Research on Evaluation, Standards, and Student Testing (CRESST); 1997.

9. Anderson RC. Some reflections on the acquisition of knowledge. Educational Researcher 1984;13:5-10.

10. Albert D, Steiner C. Representing Domain Knowledge by Concept Maps: How to Validate Them? Graz University of Technology I TU Graz · Knowledge Technologies Institute; 2005.

11. Simon HA. The Architecture of Complexity, Proceedings of the American Philosophical Society 1962;106:467-82.

12. Yao J, Gu M. Conceptology: Using Concept Map for Knowledge Representation and Ontology Construction. Journal of Networks 2013;8:1708-12.

13. Khayut B. Modeling of Intelligent System Thinking in Complex Adaptive Systems. Procedia Computer Science 2014. doi: 10.1016/j.procs.2014.09.043.

14. Aajli A, Karim A. Towards a new approach for constructing concept maps based on fuzzy logic. Proceedings of the international conference on Education and Modern Educational Technologies 2014; Dec 10-12; New Taipei City, Taiwan International Association for Development of the Information Society; 2014.

15. Žubrinić, Carića Ć. Automatic creation of a concept map. Available online: https://bib.irb.hr/datoteka/578611. KZubrinic-KvalifikacijskiRad.pdf

16. LaNoue M, Mills G, Cunningham A, et al. Concept Mapping as a Method to Engage Patients in Clinical Quality Improvement, Annals of Family Medicine 2016. doi: 10.1370/afm.1929.

17. Gurupur V, Sakoglu U, Jain GP, et al. Semantic Requirements Sharing Approach to Develop Software Systems Using Concept Maps and Information Entropy: A Personal Health Information System Example. Advances in Engineering Software 2014;70:25-35.

18. Jain GP, Gurupur VP, Faulkenberry ED. Artificial intelligence-based student learning evaluation tool, Proceedings of the 2013 IEEE Global Engineering Education Conference (EDUCON), Berlin: IEEE Education Society; 2013.

19. Karla PR, Gurupur V. C-PHIS: A Concept Map-Based Knowledge Base Framework to Develop Personal Health Information Systems. Journal of Medical Systems 2013. doi: 10.1007/s10916-013-9970-3.

20. Nasir A, Gurupur V, Liu X. A new paradigm to analyze data completeness of patient data. Applied Clinical Informatics 2016. doi: 10.4338/ACI-2016-04-RA-0063.

21. Alafaireet P, Bouras A, Houghton HL, et al. Applying Concept Mapping to Solving In-Patient Mental Health Recidivism. Missouri Medicine 2015;112:63-6.

22. Leyns CC, Maeseneer JD, Willems S. Using concept mapping to identify policy options and interventions towards people centered health care services: a multi stakeholders perspective. International Journal for Equity in Health 2018. doi: 10.1186/s12939-018-0895-9. 
23. Gurupur VP, Tanik, MM. A System for Building Clinical Research Applications using Semantic Web-Based Approach. Journal of Medical Systems 2012;36:53-9.

24. Wan T, Gurupur V. Understanding the Difference between Healthcare Informatics and Healthcare Data Analytics in the Present State of Health Care Management. Health Services Research \& Managerial Epidemiology 2020;7:2333392820952668.

25. Gurupur V, Wan TTH. Inherent Bias in Artificial Intelligence-Based Decision Support Systems for Healthcare. Medicina 2020;56:141.

26. Gurupur V, Shettian KP, Xu P, et al. Identifying the Readiness of Patients in Implementing Telemedicine in Northern Louisiana for an Oncology Practice. Health

doi: $10.21037 /$ ht-21-12

Cite this article as: Gurupur VP. A review on advances in design and development of complex adaptive systems for healthcare using concept maps. Health Technol 2021;5:8.
Informatics J 2017;23:181-96.

27. Kulkarni SA, Pannu JS, Koval AV, et al. A Brief Analysis of Key Machine Learning Methods for Predicting Medicare Payments Related to Physical Therapy Practices in the United States. Information 2021;12:57.

28. Gurupur V, Gutierrez R. Designing the Right Framework for Healthcare Decision Support. Journal of Integrated Design and Process Science 2016. doi: 10.3233/jid-20160001.

29. Rudraraju R, Najim L, Gurupur V, et al. A Learning Environment Based on Knowledge Storage and Retrieval Using Concept Maps, Proceedings of the IEEE Southeast Conference 2014, March 13-16, Lexington, KY; 2014. 